Correspondence

K. T. Shanmugam shan@ufl.edu

Received 17 October 2011

Revised 22 January 2012

Accepted 10 February 2012

\section{Amino acid substitutions at glutamate-354 in dihydrolipoamide dehydrogenase of Escherichia coli lower the sensitivity of pyruvate dehydrogenase to $\mathrm{NADH}$}

\author{
Zhentao Sun, ${ }^{1,2}$ Phi Minh Do, ${ }^{2}$ Mun Su Rhee, ${ }^{2}$ Lakshmanan Govindasamy, ${ }^{3}$ \\ Qingzhao Wang, ${ }^{2}$ Lonnie O. Ingram ${ }^{2}$ and K. T. Shanmugam ${ }^{2}$ \\ ${ }^{1}$ College of Resources and Environmental Sciences, China Agricultural University, PR China \\ ${ }^{2}$ Department of Microbiology and Cell Science, University of Florida, Gainesville, FL 32611, USA \\ ${ }^{3}$ Department of Biochemistry and Molecular Biology, University of Florida, Gainesville, FL 32611, \\ USA
}

Pyruvate dehydrogenase (PDH) of Escherichia coli is inhibited by NADH. This inhibition is partially reversed by mutational alteration of the dihydrolipoamide dehydrogenase (LPD) component of the PDH complex (E354K or H322Y). Such a mutation in Ipd led to a PDH complex that was functional in an anaerobic culture as seen by restoration of anaerobic growth of a $p f I B, I d h A$ double mutant of $E$. coli utilizing a $\mathrm{PDH}$ - and alcohol dehydrogenase-dependent homoethanol fermentation pathway. The glutamate at position 354 in LPD was systematically changed to all of the other natural amino acids to evaluate the physiological consequences. These amino acid replacements did not affect the $\mathrm{PDH}$-dependent aerobic growth. With the exception of $\mathrm{E} 354 \mathrm{M}$, all changes also restored PDH-dependent anaerobic growth of and fermentation by an IdhA, pflB double mutant. The PDH complex with an LPD alteration E354G, E354P or E354W had an approximately 20-fold increase in the apparent $K_{\mathrm{i}}$ for $\mathrm{NADH}$ compared with the native complex. The apparent $K_{m}$ for pyruvate or $\mathrm{NAD}^{+}$for the mutated forms of $\mathrm{PDH}$ was not significantly different from that of the native enzyme. A structural model of LPD suggests that the amino acid at position 354 could influence movement of NADH from its binding site to the surface. These results indicate that glutamate at position 354 plays a structural role in establishing the NADH sensitivity of LPD and the PDH complex by restricting movement of the product/substrate NADH, although this amino acid is not directly associated with $N A D(H)$ binding.

\section{INTRODUCTION}

Pyruvate is at a pivotal point in the carbon and energy metabolism of Escherichia coli. During aerobic growth, pyruvate is oxidatively decarboxylated to acetyl-CoA by pyruvate dehydrogenase $(\mathrm{PDH})$ (EC 1.2.4.1) and further oxidized through the enzymes of the TCA cycle and respiratory chain. During anaerobic growth, due to the large decrease in $\mathrm{PDH}$ activity in vivo, pyruvate formatelyase (PFL) serves as the primary route for synthesis of acetyl-CoA and carbon dioxide, primary metabolites required for cell growth (Fig. 1) (Bock \& Sawers, 1996; Clark, 1989; Guest, 1995; Murarka et al., 2010; Sawers \&

Abbreviations: $\mathrm{LDH}$, lactate dehydrogenase; $\mathrm{PDH}$, pyruvate dehydrogenase; PFL, pyruvate formate-lyase.

A set of supplementary methods, a supplementary figure and three supplementary tables are available with the online version of this paper.
Clark, 2004). Although PDH activity is very low during anaerobic growth, all genes encoding the $\mathrm{PDH}$ complex are transcribed and translated under these conditions (Cassey et al., 1998; Hansen \& Henning, 1966; Kaiser \& Sawers, 1994; Kim et al., 2008; Snoep et al., 1993). The presence of a functional PDH complex in cell extracts of anaerobically grown E. coli suggests that the lack of $\mathrm{PDH}$ activity in vivo is due to regulation of the enzyme activity by intracellular metabolites. During fermentative growth, NADH pools are high in comparison to aerobic growth, and NADH has emerged as the primary inhibitor of PDH activity (de Graef et al., 1999; Hansen \& Henning, 1966; Kim et al., 2008; Schmincke-Ott \& Bisswanger, 1981; Shen \& Atkinson, 1970). Inhibition of the PDH complex by NADH can be reduced by a single mutation in the dihydrolipoamide dehydrogenase (LPD; EC 1.8.1.4) subunit (either H322Y or E354K) of the PDH complex (Kim et al., 2008). These mutations increased the apparent $K_{\mathrm{i}}$ for $\mathrm{NADH}$, and thus 


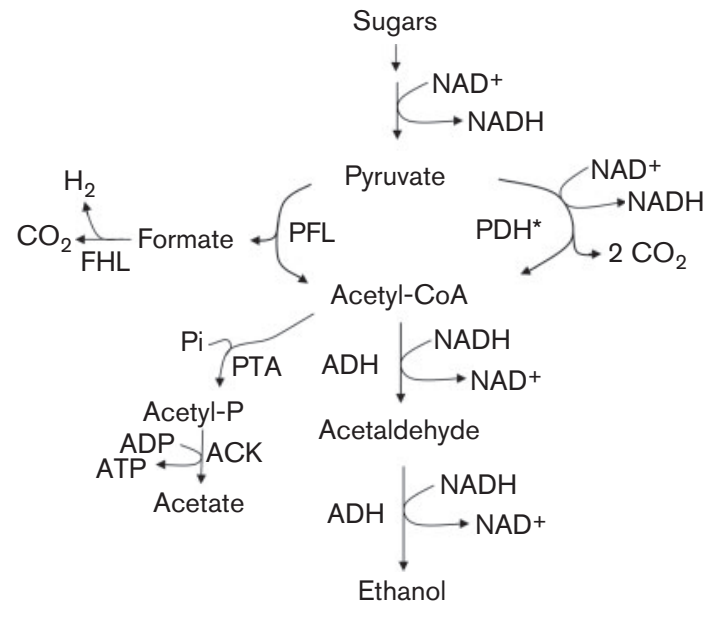

Fig. 1. Fermentation pathways of $E$. coli leading to ethanol production in the wild-type and ethanologenic derivatives. In the wild-type, pyruvate is converted to acetyl-CoA by PFL. The reductant released during this oxidative decarboxylation is lost as $\mathrm{H}_{2}$ through formate. Due to this loss, an equimolar amount of acetate and ethanol is produced to maintain redox balance. In the ethanologenic derivatives, $\mathrm{PDH}^{*}$ is active during anaerobic growth and with active $\mathrm{PDH}^{*}$, the $[\mathrm{H}]$ released at this step is captured as $\mathrm{NADH}$. The yield of two NADHs per acetyl-CoA produced through this pathway supports complete conversion of acetyl-CoA to ethanol to maintain redox balance. ACK, acetate kinase; $A D H$, alcohol dehydrogenase; $\mathrm{FHL}$, formate hydrogen-lyase; $\mathrm{PDH}^{*}$, pyruvate dehydrogenase complex with a mutation in the dihydrolipoamide dehydrogenase component; PTA, phosphotransacetylase.

caused a reduction in the extent of inhibition. Glutamate 354 is located within the central domain of LPD and is not recognized as a constituent of the $\mathrm{NAD}^{+}$binding pocket. However, a mutation in human LPD at position 358 (the analogous position in E. coli LPD is 351 ) has been previously reported to alter $\mathrm{NAD}^{+}$binding (Brautigam et al., 2005). Other mutations in the central domain of LPD have been reported but none were identified as influencing NADH inhibition (Benen et al., 1991; Brautigam et al., 2005; Cameron et al., 2006; Hopkins \& Williams, 1995).

A null mutant of E. coli lacking PDH activity requires acetate for aerobic growth (Russell \& Guest, 1990) but had no detectable phenotype during anaerobic growth due to the presence of PFL (Fig. 1). During anaerobic growth, acetyl-CoA serves as a key intermediate for biosynthesis and as an electron acceptor to maintain redox balance (Bock \& Sawers, 1996; Sawers \& Clark, 2004). Mutant E. coli K-12 strains lacking both PFL and lactate dehydrogenase (LDH) activities are unable to grow anaerobically due to their inability to maintain redox balance (Clark, 1989; Kim et al., 2007). Although native PDH complex is present in the cytoplasm of anaerobic E. coli (Hansen \& Henning, 1966; Kaiser \& Sawers, 1994; Murarka et al., 2010; Snoep et al., 1993), it is apparently inhibited by $\mathrm{NADH}$, and the residual activity was insufficient to support anaerobic growth (Kim et al., 2007, 2008; Snoep et al., 1993). PDH with an LPD alteration (H322Y or E354K) restored anaerobic growth of an $l d h A, p f l B$ double mutant by providing acetyl-CoA for redox balance (Kim et al., 2008). This triple mutant produced ethanol by coupling $\mathrm{PDH}$ with alcohol dehydrogenase (Fig. 1).

Mutated PDH (NADH-insensitive) has potential industrial applications by doubling the NADH yield available for production of reduced fermentation products such as ethanol without the need for foreign genes. Although either the H322Y or E354K mutation supported anaerobic growth of E. coli K-12 strains, anaerobic growth rates of these mutants were lower than those of the wild-type strain (Kim et al., 2007) and other mutations in LPD may be superior for biotechnological applications (Kim et al., 2008). In this study, mutant forms of PDH were constructed in which glutamate at position 354 of LPD was systematically replaced by other amino acids. The resulting strains were evaluated for anaerobic growth, ethanol production and sensitivity to inhibition by NADH.

\section{METHODS}

Bacterial strains and plasmids. E. coli strains and plasmids used in this study are listed in Table S1 (available with the online version of this paper). All strains are derivatives of K-12.

Media and growth conditions. Luria broth (LB) and mineral salts medium were prepared as described previously (Lee et al., 1985). Sugars were added to sterile medium at an initial concentration of $3 \mathrm{~g}$ $1^{-1}$ for aerobic growth and $10 \mathrm{~g} \mathrm{l}^{-1}$ for anaerobic growth. Aerobic cultures were grown in $10 \mathrm{ml}$ medium in $125 \mathrm{ml}$ Erlenmeyer flasks at $37{ }^{\circ} \mathrm{C}$ in a shaker (200 r.p.m.). Batch fermentation without $\mathrm{pH}$ control was performed in screw-cap tubes $(13 \times 100 \mathrm{~mm})$ in which the appropriate medium was added to the top of the tube. Batch fermentation at $\mathrm{pH} 7.0$ with $\mathrm{pH}$ control was carried out in $500 \mathrm{ml}$ vessels containing $250 \mathrm{ml} \mathrm{LB}$ with $30 \mathrm{~g}$ glucose $\mathrm{l}^{-1}$ (Underwood et al., 2002). Inoculum ( $1 \%, \mathrm{v} / \mathrm{v})$ for the fermentations was grown aerobically at $37{ }^{\circ} \mathrm{C}$, overnight. If needed, antibiotics were added at an initial concentration of $100 \mathrm{mg}$ ampicillin $\mathrm{l}^{-1}$ or $50 \mathrm{mg}$ kanamy$\operatorname{cin} 1^{-1}$ for plates and $20 \mathrm{mg}$ kanamycin $1^{-1}$ for liquid medium.

PCR-based site-directed mutagenesis of IpdA in plasmid pZS3. The dihydrolipoamide dehydrogenase gene $\left(l p d^{+}\right)$of $E$. coli strain W3110 was cloned into plasmid pBR322 (pZS3). For construction of plasmid pZS3, the complete lpd DNA (2.35 kbp) including the promoter and terminator region of the native gene was amplified by PCR from genomic DNA (see supplementary methods). The forward primer (5'-GCGAGCTAGCGCGGTTGCTTCACCATCTC-3') and the reverse primer (5'-GCAATGCCCGAGGCGTATTCAGTCCGCATCAC- $\left.3^{\prime}\right)$ contained NheI and AvaI restriction endonuclease cleavage site (underlined), respectively. The PCR product and plasmid pBR322 were digested with restriction enzymes NheI and AvaI, and ligated together to construct plasmid pZS3 containing the native $l p d$ gene. The $l p d$ gene in plasmid pZS3 was mutagenized using PCR with two synthetic oligonucleotide primers containing the expected mutations [positions 1060-1062 of lpd representing glutamate in the native protein (A in the ATG codon of the lpd gene was defined as position 1]. The forward primer contained the following sequence: $5^{\prime}$ CGCCTATACCNNNCCAGAAGTTG-3'. The underlined 'NNN' represent the codons for the 18 different amino acids except for 
glutamic acid and lysine. The E354K mutation, lpd101, has been described previously (Kim et al., 2008) and glutamate at position 354 is the natural amino acid. The reverse primer sequence was as follows: 5'-ATGGACGGGATAACTTTCGGATC-3'. Using these different primer pairs, the entire plasmid pZS3 (5518 bp) was amplified. After purification, the PCR product was treated with T4 polynucleotide kinase, and circularized by T4 DNA ligase. The ligation product was transformed into E. coli Top10 chemical competent cells. The plasmid DNA isolated from these transformants was sequenced to confirm the specific introduced mutation in the lpd gene.

Construction of mutants. Construction of various mutant strains utilized standard techniques (Ausubel et al., 1987; Davis et al., 1980; Miller, 1972). Gene deletions in E. coli were constructed as described previously (Datsenko \& Wanner, 2000) and verified by PCR. Two triple mutants of E. coli used in this study, strains YK100 and ZS2 [ $\Delta(f \circ c A-p f l B), \Delta l d h A$ and $\Delta l p d)$; Table S1], could not grow aerobically in glucose mineral salts medium and anaerobically in any of the media tested. These strains were used to evaluate the phenotypic properties conferred by various plasmids with different $l p d$ mutations.

Transfer of the Ipd mutation to the chromosome of $E$. coli. Three lpd alleles that supported anaerobic growth of strains YK100 and ZS2 (E354G, E354P and E354W) were amplified by PCR from appropriate plasmids (Table S1) and verified by sequencing. After purification, the linear PCR product was electroporated into E. coli strain ZS4 (strain ZS2 with pKD46) as described previously (Datsenko \& Wanner, 2000). Transformants that grew in glucose mineral salts medium (aerobic) were selected and tested for kanamycin sensitivity and anaerobic growth. The chromosomal $l p d$ gene from these derivatives was amplified by PCR and sequenced to confirm the presence of the desired lpd mutation.

Purification of PDH complex. The PDH complex was purified as described previously with minor modifications (Bisswanger, 1981; Kim et al., 2008) and the details are listed in the Supplementary Methods. Protein purity was determined by SDS-PAGE (Laemmli, 1970) and enzyme activity was determined immediately using freshly prepared protein.

Purification of LPD. Purification of LPD followed the same procedure described above for purification of PDH up to the $150000 \mathrm{~g}$ centrifugation step. After the centrifugation step at $150000 \mathrm{~g}$, the supernatant had significant LPD activity. This fraction was filtered through a $0.22 \mu \mathrm{m}$ filter and chromatographed through a hydroxyapatite column and gel filtration column as for PDH purification. The LPD-containing fractions were combined and concentrated. If needed, LPD was further purified using a Q-Sepharose column $(2.0 \times 20.0 \mathrm{~cm}$; GE) and the protein was eluted with a linear $\mathrm{NaCl}$ gradient $(0-500 \mathrm{mM}$ in phosphate buffer, $\mathrm{pH} 7.5)$. Fractions with LPD activity were combined and dialysed against phosphate buffer. Protein purity was determined by SDS-PAGE (Laemmli, 1970).

Enzyme assays. LPD activity was measured in both the forward and reverse reaction as described by Patel \& Hong (1998) and the reaction conditions are presented in the Supplementary Methods. One unit of enzyme activity was defined as the amount of enzyme required for oxidation of $1 \mu \mathrm{mol} \mathrm{NADH}$ (or reduction of $1 \mu \mathrm{mol} \mathrm{NAD}{ }^{+}$) $\mathrm{min}^{-1}$ $(\mathrm{mg} \text { protein })^{-1}$. Both reactions were performed at room temperature.

A standard assay for PDH complex was based on pyruvate-dependent reduction of $\mathrm{NAD}^{+}$at $340 \mathrm{~nm}\left(\varepsilon=6220 \mathrm{M}^{-1} \mathrm{~cm}^{-1}\right)$ at room temperature, as described previously (Kim et al., 2008). The reaction was started by addition of pyruvate. Enzyme activity is defined as $\mu$ mol NADH produced $\min ^{-1}$ (mg protein $)^{-1}$. The effect of NADH on enzyme activity was determined using the same reaction mixture with addition of various concentrations of NADH.
Homology modelling of E. coli LPD. Since a structure of E. coli LPD is not available, Neisseria meningitidis LPD X-ray structure (PDB-ID: 1OJT) (Li de la Sierra et al., 1997) was used as a template for generation of an E. coli LPD model using the SWISS-MODEL program (Arnold et al., 2006). Structures were superposed with each other for comparison using the COOT program (Emsley et al., 2010). The E. coli LPD model was evaluated with the PROCHECK program (Laskowski et al., 1993) to confirm the molecular geometry accuracy of the model. The figures were made and ray-traced with the PYMOL program (Delano, 2002).

Analytical methods. For determination of $\mathrm{NAD}^{+}$and NADH pools, aerobic cultures were grown in LB medium $(10 \mathrm{ml}$ in $125 \mathrm{ml}$ flask) on a shaker at 200 r.p.m. $\left(37^{\circ} \mathrm{C}\right)$. Anaerobic cultures were grown in $\mathrm{LB}+$ glucose $(1 \% ; \mathrm{w} / \mathrm{v})$ in filled tubes without $\mathrm{pH}$ control. Aerobic cultures were inoculated $(1 \%$; v/v) from an aerobic mid-exponentialphase culture. Anaerobic cultures were inoculated to an initial $\mathrm{OD}_{420}$ of 0.1 (measured with a Spectronic 20) from an anaerobic culture grown in the same medium. Cells were harvested at mid-exponential phase of growth, and $\mathrm{NAD}^{+}$and $\mathrm{NADH}$ concentrations in cell extracts were determined essentially as described by Snoep et al. (1990) using an EnzyChrom $\mathrm{NAD}^{+} / \mathrm{NADH}$ assay kit (BioAssay Systems).

Glucose and fermentation products were determined by HPLC using an HP1090 chromatograph (Agilent Technologies) fitted with an Aminex HPX-87H column (Bio-Rad Laboratories) (Underwood et al., 2002). Cell density was monitored at $420 \mathrm{~nm}$. Protein concentration was determined by the Bradford method with BSA as the standard (Bradford, 1976).

\section{RESULTS AND DISCUSSION}

The anaerobic growth phenotype of strain SE2378, an $l d h A$, pflB, lpd101 mutant of E. coli, is based on the lpd101 mutation (E354K) that lowered the sensitivity of the PDH complex to NADH (Kim et al., 2007, 2008). This mutant produced ethanol as the primary fermentation product, an indication of $\mathrm{NADH}$-insensitive $\mathrm{PDH}^{\star}$-supported anaerobic growth (Fig. 1). To evaluate the effect of other amino acids at position 354 of LPD on supporting anaerobic growth of an $l d h A$, pflB mutant, the 354-glutamate was changed to other natural amino acids and the effect of these changes on aerobic and anaerobic growth was determined.

\section{Growth and fermentation properties of LPD mutants}

E. coli strain ZS2 contains three mutations (ldhA, pflB and $\Delta l p d)$ and can be used to screen for a functional PDH complex (plasmid) under aerobic conditions and for an $\mathrm{NADH}$-insensitive complex under anaerobic growth conditions. PDH mutations at this amino acid position of LPD were supplied to strain ZS2 from plasmids to compare their effectiveness for aerobic growth, anaerobic growth and ethanol production. All amino acid replacements of E354 in LPD supported aerobic growth in glucose mineral salts medium (Table S2). All amino acid replacements except methionine also restored anaerobic growth of strain ZS2, although the aerobic growth rate and cell yield of strain ZS2 carrying E354M were similar to that of the same 
Table 1. Anaerobic growth and fermentation profiles of $E$. coli strains with different $I p d$ mutations

Fermentations were conducted in LB with 30 g glucose $1^{-1}$ with $\mathrm{pH}$ control (pH 7.0) at $37{ }^{\circ} \mathrm{C}$. UD, Undetectable below $0.5 \mathrm{mM}$. Data shown are means \pm SD.

\begin{tabular}{|c|c|c|c|c|c|c|c|c|c|c|}
\hline \multirow[t]{2}{*}{ Strain LF } & \multirow[t]{2}{*}{ LPD alteration } & \multirow{2}{*}{$\begin{array}{c}\text { Growth rate } \\
\qquad\left(h^{-1}\right)\end{array}$} & \multirow{2}{*}{$\begin{array}{l}\text { Cell yield } \\
\quad\left(\mathrm{g} \mathrm{l}^{-1}\right)\end{array}$} & \multirow{2}{*}{$\begin{array}{l}\text { Glucose consumed } \\
\qquad(\mathrm{mM})\end{array}$} & \multicolumn{5}{|c|}{ Product (mM) } & \multirow{2}{*}{$\begin{array}{l}\text { Ethanol } \\
\text { yield }^{*}\end{array}$} \\
\hline & & & & & Acetate & Formate & Lactate & Succinate & Ethanol & \\
\hline YK1 & E354K & 0.59 & 1.36 & $163.0 \pm 2.5$ & $10.4 \pm 0.4$ & UD & $11.6 \pm 1.0$ & $8.7 \pm 1.4$ & $305.4 \pm 9.0$ & $93.7 \pm 0.03$ \\
\hline ZS28 & E354G & 0.59 & 1.52 & $166.6 \pm 2.3$ & $11.4 \pm 1.0$ & UD & $13.0 \pm 0.8$ & $11.0 \pm 0.4$ & $288.6 \pm 1.4$ & $86.6 \pm 0.01$ \\
\hline ZS34 & E354P & 0.56 & 1.52 & $165.1 \pm 0.8$ & $14.9 \pm 1.7$ & UD & $13.5 \pm 0.3$ & $12.6 \pm 0.7$ & $287.7 \pm 7.0$ & $87.1 \pm 0.02$ \\
\hline
\end{tabular}

${ }^{\star}$ Ethanol yield is presented as a percentage of the theoretical maximum.

strain with a $l p d^{+}$derivative. This differential effect of E354M mutation suggests that this specific substitution did not eliminate the activity of the PDH complex and also did not alter its sensitivity to inhibition by NADH. This substitution was not further investigated. Modelling this substitution together with others could be used to delineate the boundaries of the change in structure needed to minimize NADH sensitivity of the PDH complex.

All other changes that replaced glutamate at 354 of LPD supported anaerobic growth and production of ethanol as the main fermentation product, as seen previously with the E354K mutation (Kim et al., 2007, 2008). Although the culture medium from strain ZS2 with the LPD substitutions E354L, E354Q and E354T had a lower concentration of ethanol compared with others after the first $24 \mathrm{~h}$ (Table S2), the ethanol titre of these cultures increased to similar levels after $48 \mathrm{~h}$ of growth. These results suggest that only glutamate or methionine at position 354 of LPD renders the enzyme sensitive to NADH as seen by their inability to support anaerobic growth of strain ZS2 (Table S2).

Five of the mutations leading to the following changes, E354G, E354S, E354H, E354P and E354W, were selected based on the side chain of the substituted amino acid and tested in another triple mutant, strain YK100 that is also anaerobic growth minus $(l d h A, p f l B, l p d)$. PDH complexes containing these mutated forms of LPD supported anaerobic growth of strain YK100 also suggesting potential $\mathrm{NADH}$ insensitivity of the $\mathrm{PDH}^{*}$ complexes carrying these alterations. Three of the LPD alterations (E354G, E354P and $\mathrm{E} 354 \mathrm{~W}$ ) were transferred to the chromosome and verified by PCR and sequencing.

Aerobic growth rate and cell yield of the chromosomal lpd mutants were similar to those of the wild-type strain W3110. In pH-controlled fermentations, E. coli wild-type strain W3110 grew at a specific growth rate of about $1.1 \mathrm{~h}^{-1}$ while the three new LPD mutants (E354G, E354P and $\mathrm{E} 354 \mathrm{~W}$ ) only supported anaerobic growth at about half of the growth rate of the wild-type (Table 1), a level that was similar to that of strain YK1 with the previously reported E354K mutation (Kim et al., 2008). However, the cell yield of the wild-type and the mutants, determined at the end of growth phase, were similar. The primary fermentation product of these LPD mutants was ethanol except for strain W3110 that produced a mixture of products, as expected (Table 1, Fig. S1). The lower growth rate of the lpd mutants can be correlated with the lower rate of glucose consumption (about half that of the wildtype) since the yield of cells per glucose consumed was similar to that of the wild-type (Table S3). The lower rate of sugar consumption by the mutants could be a result of a low in vivo PDH activity that is limiting production of acetyl-CoA from pyruvate, a required electron acceptor, to maintain redox balance in these mutants. In spite of the

Table 2. Kinetic characteristics of the PDH complex isolated from E. coli strains with different LPD changes

Enzymes were purified from E. coli strains ZS3 (native protein), ZS28 [LPD (E354G)], ZS34 [LPD (E354P)] and ZS40 [LPD (E354W)].

\begin{tabular}{|lccccc|}
\hline LPD change & $\boldsymbol{K}_{\mathbf{m}}$ (pyruvate) $(\mathbf{m M})$ & $\boldsymbol{K}_{\mathbf{m}}\left(\mathbf{N A D}^{+}\right)(\mathbf{m M})$ & $\boldsymbol{K}_{\mathbf{i}}(\mathbf{N A D H})(\boldsymbol{\mu M})$ & $\boldsymbol{V}_{\text {max }^{*}}$ & Specific activity $^{\star}$ \\
\hline Native & 0.43 & 0.28 & 1.34 & 66.45 & 25.3 \\
E354G & 0.34 & 0.17 & 23.40 & 71.73 & 18.6 \\
E354P & 0.32 & 0.51 & 22.60 & 97.40 \\
E354W & 0.35 & 0.26 & 20.30 & 95.20 \\
\hline
\end{tabular}

${ }^{*} \mu \mathrm{mol} \min ^{-1}(\mathrm{mg} \text { protein })^{-1}$. 

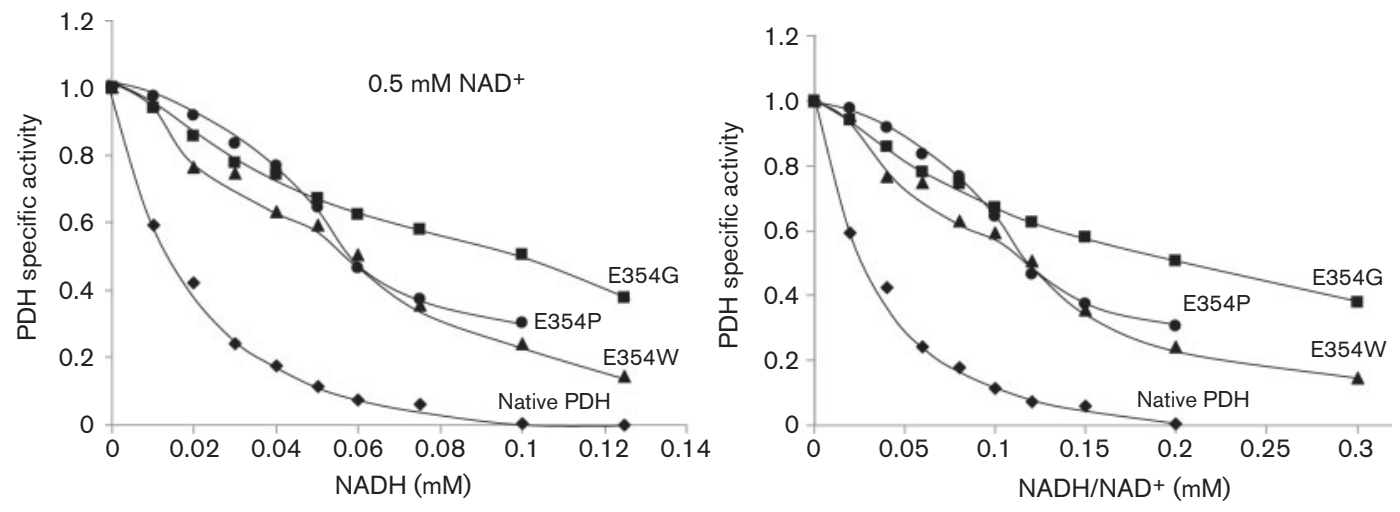

Fig. 2. Effect of LPD alteration on $\mathrm{NADH}$ sensitivity of $\mathrm{PDH}$ complex of $E$. coli. PDH activity was determined with varying concentrations of $\mathrm{NADH}$ at a fixed $\mathrm{NAD}^{+}$concentration of $0.5 \mathrm{mM}$. The specific activity of the native PDH complex without $\mathrm{NADH}$ was 25.32 U. The specific activities of the three PDH complexes with LPD alterations E354G, E354P and E354W without NADH were $18.63 \mathrm{U}, 14.11 \mathrm{U}$ and $18.66 \mathrm{U}$, respectively. The values presented are the fraction of the activity of each enzyme without added NADH.

plausible limitation at the PDH level, the three mutated forms of the $\mathrm{PDH}$ complex appear to be active during anaerobic growth, suggesting a reduced level of $\mathrm{NADH}$ sensitivity of the complex.

\section{Biochemical properties of PDH from the LPD mutants}

The PDH complex was purified from the wild-type strain and the three selected mutants with chromosomally integrated lpd mutations. Kinetic properties of these enzymes were determined, especially inhibition of activity by NADH. The native complex had the highest specific activity of 25.3 units under the reported assay condition while the specific activities of the three altered proteins

Table 3. $[\mathrm{NADH}]:\left[\mathrm{NAD}^{+}\right]$ratio of wild-type $E$. coli and $I p d$ mutants grown under aerobic and anaerobic conditions

\begin{tabular}{|llcc|}
\hline \multirow{2}{*}{ Strain } & Relevant genotype & \multicolumn{2}{c|}{$[\mathbf{N A D H}]:\left[\mathrm{NAD}^{+}\right]$} \\
\cline { 3 - 4 } & & Aerobic & Anaerobic \\
\hline W3110 & Wild-type & 0.13 & 0.22 \\
AH242 & $l d h A, p f l B$ & 0.22 & $0.76^{*}$ \\
ZS2 & $l d h A, p f l B, l p d$ & 0.23 & $0.33^{*}$ \\
YK1 & $l d h A, p f l B, l p d 101$ & 0.23 & 0.36 \\
ZS28 & $l d h A, p f l B, l p d 109$ & 0.27 & 0.38 \\
ZS34 & $l d h A, p f l B, l p d 115$ & 0.16 & 0.41 \\
ZS40 & $l d h A, p f l B, l p d 121$ & 0.18 & 0.43 \\
& & & \\
\hline
\end{tabular}

*Since strains AH242 and ZS2 are anaerobic-growth-negative, an aerobic culture at mid-exponential phase of growth was transferred to anaerobic conditions and cells were harvested after $2 \mathrm{~h}$ incubation at $37{ }^{\circ} \mathrm{C}$. Presented results are the average of two independent experiments. were slightly lower (Table 2). Among the three mutated forms of the PDH complex, the E354P form of the protein had the lowest specific activity, about $55 \%$ of the activity of the native protein. However, the $V_{\max }$ of the three PDH complexes with a mutated form of LPD was similar to that of the native PDH or higher. The apparent $K_{\mathrm{m}}$ values for the substrates pyruvate and $\mathrm{NAD}^{+}$were not significantly different among the three mutated forms of the protein and the native enzyme. The apparent $K_{\mathrm{i}}$ for NADH for the native complex was determined to be $1.34 \mu \mathrm{M}$ (Table 2, Fig. 2), a value similar to other reported values (Bisswanger \& Henning, 1971; Kim et al., 2008). In contrast, the apparent $K_{\mathrm{i}}$ for $\mathrm{NADH}$ for the three mutated forms of $\mathrm{PDH}$ was about 15 -fold higher than that of the native PDH complex (Table 2). In agreement with the differences in apparent $K_{\mathrm{i}}$, the PDH complex isolated from the mutant strains was also less sensitive to inhibition by NADH (Fig. 2). At an $\mathrm{NADH}$ concentration of $50 \mu \mathrm{M}$, native enzyme was inhibited by more than $90 \%$. Increasing the $\mathrm{NAD}^{+}$ concentration to $1.0 \mathrm{mM}$ and $2.0 \mathrm{mM}$ decreased the extent of inhibition by $50 \mu \mathrm{M} \mathrm{NADH}$ to 71 and $46 \%$, respectively, in confirmation of competitive inhibition of the PDH complex by NADH. Irrespective of the $\mathrm{NAD}^{+}$ and NADH concentration, an $[\mathrm{NADH}]:\left[\mathrm{NAD}^{+}\right]$ratio of about 0.1 inhibited the native PDH complex by about $90 \%$ (Fig. 2).

At the same $[\mathrm{NADH}]:\left[\mathrm{NAD}^{+}\right]$ratio of 0.1 , the three $\mathrm{PDH}$ complexes with the LPD alteration retained about $65 \%$ of the control activity without added NADH. Although increasing the concentration of $\mathrm{NADH}$ in the assay did inhibit the PDH complexes from the mutants, this required significantly higher [NADH]. The observed increase in $V_{\max }$ for the PDH complex with the LPD alterations could arise from the lower affinity of the complex for $\mathrm{NADH}$, the product and inhibitor of the reaction (Table 2). These results show a positive correlation between reduced 
sensitivity of the PDH complex to NADH inhibition and anaerobic growth of appropriate $E$. coli mutants supported by the PDH complex.

\section{[NADH] : $\left[\mathrm{NAD}^{+}\right]$ratio of LPD mutants}

The results presented in Fig. 2 show that the native PDH is completely inhibited at an $[\mathrm{NADH}]:\left[\mathrm{NAD}^{+}\right]$ratio of 0.2 . E. coli grown anaerobically in mineral salts medium has been previously reported to have an $[\mathrm{NADH}]:\left[\mathrm{NAD}^{+}\right]$ ratio as high as 0.75 (de Graef et al., 1999). Wild-type strain W3110 grown in rich medium anaerobically had an $[\mathrm{NADH}]:\left[\mathrm{NAD}^{+}\right]$ratio of 0.22 (Table 3 ), a value that is higher than that needed for complete inhibition of $\mathrm{PDH}$ in vitro (Fig. 2). Strain AH242 lacking both LDH and PFL activities did not grow anaerobically, and when an aerobic culture of this strain was transferred to anaerobic conditions, the $[\mathrm{NADH}]:\left[\mathrm{NAD}^{+}\right]$ratio increased to 0.76 within $2 \mathrm{~h}$ since this culture could not reoxidize NADH. Part of this increase is apparently due to native $\mathrm{PDH}$ activity since deleting LPD (strain ZS2) lowered this ratio by more than twofold. All four $\mathrm{LPD}^{\star}$ mutants had a higher $[\mathrm{NADH}]:\left[\mathrm{NAD}^{+}\right]$ratio than the wild-type (Table 3 ) but a significantly lower ratio than that of strain AH242 with native PDH complex during anaerobic growth. The observed ratio of $[\mathrm{NADH}]:\left[\mathrm{NAD}^{+}\right]$in these $\mathrm{LPD}^{\star}$ mutants is apparently due to a new redox equilibrium between $\mathrm{NADH}$ production by $\mathrm{PDH}^{*}$ and $\mathrm{NADH}$ oxidation by alcohol dehydrogenase in ethanol production (Fig. 1). Anaerobic growth of these mutants even at this ratio (about 0.4 ) that is higher than that of the wild-type (about 0.2 ) is apparently due to the $l p d$ mutation that lowered the affinity of the PDH complex for NADH (Table 2).

\section{Biochemical properties of altered LPD}

Since the mutation that lowered the sensitivity of PDH complex to NADH inhibition resides in the LPD component, the LPDs from each of the three mutants and the native enzyme were purified and their kinetic properties were determined. The apparent $K_{\mathrm{m}}$ for $\mathrm{NAD}^{+}$ for the native LPD was $0.14 \mathrm{mM}$ in the forward reaction (Table 4). At seven times the apparent $K_{\mathrm{m}}$ value of $\mathrm{NAD}^{+}$ $(1.0 \mathrm{mM}), \mathrm{NADH}$ at $0.1 \mathrm{mM}$ inhibited $90 \%$ of the LPD activity (Fig. 3a). Activity of the native LPD was completely inhibited by $0.14 \mathrm{mM} \mathrm{NADH}$. As expected, increasing the $\mathrm{NAD}^{+}$concentration partially reversed NADH inhibition as the ratio of $\mathrm{NAD}^{+}$to $\mathrm{NADH}$ increased (data not presented). The $90 \%$ inhibition of the LPD activity at an $\left[\mathrm{NAD}^{+}\right]$: [NADH] ratio of 10 was reduced to about $70 \%$ inhibition by a twofold increase in this ratio at the same $0.1 \mathrm{mM}$ NADH.

Although the apparent $K_{\mathrm{m}}$ for $\mathrm{NAD}^{+}$for the three mutated forms of LPD was similar to that of the native protein, the apparent $K_{\mathrm{i}}$ for NADH was at least three times higher than that of the native protein (Table 4). The higher apparent $K_{\mathrm{i}}$ values for NADH led to a lower level of
Table 4. Kinetic characteristics of the LPD isolated from E. coli strains with different changes

Enzymes were purified from $E$. coli strains ZS3 (native protein), ZS28 [LPD (E354G)], ZS34 [LPD (E354P)] and ZS40 [LPD (E354W)]. The reported values are for the LPD forward reaction utilizing dihydrolipoic acid and $\mathrm{NAD}^{+}$as substrates.

\begin{tabular}{|lcc|}
\hline LPD change & $\boldsymbol{K}_{\mathbf{m}}\left(\mathbf{N A D}^{+}\right)(\mathbf{m M})$ & $\boldsymbol{K}_{\mathbf{i}}(\mathbf{N A D H})(\boldsymbol{\mu M})$ \\
\hline Native & 0.14 & 2.20 \\
E354G & 0.15 & 7.36 \\
E354P & 0.19 & 6.74 \\
E354W & 0.14 & 6.57 \\
\hline
\end{tabular}

inhibition of LPD activity by NADH (Fig. 3a). The three mutated forms of the enzyme had slightly different NADH inhibition profiles from the native enzyme. At an NADH concentration of $0.1 \mathrm{mM}$, the $\mathrm{E} 354 \mathrm{G}$ form of the protein still retained about $60 \%$ of its activity while the native protein lost about $90 \%$ of its activity. The other two mutated forms of the protein had NADH inhibition profiles that were similar to that of E354G-LPD up to an $\mathrm{NADH}$ concentration of about $0.08 \mathrm{mM}$ and differed significantly after that concentration (Fig. 3a).

In the reverse reaction, LPD is known to require $\mathrm{NAD}^{+}$for activation (Kim et al., 2008; Sahlman \& Williams, 1989; Scouten \& McManus, 1971) and a native LPD activity of about 10 units was increased by about 15 -fold by $0.4 \mathrm{mM}$ $\mathrm{NAD}^{+}$(Fig. 3b). However, as seen previously with the E354K form of the enzyme (Kim et al., 2008), the three mutated forms of LPD had higher activity in the absence of $\mathrm{NAD}^{+}$, and the amount of $\mathrm{NAD}^{+}$required for full activation was also lower than the amount required for full activation of the native enzyme. Among the mutated forms studied, activity of the E354G form of the enzyme without $\mathrm{NAD}^{+}$(128 units) was almost as high as that of the fully activated native enzyme (154 units). This activity of E354G-LPD was only increased by about 1.5 -fold to 200 units by $0.1 \mathrm{mM} \mathrm{NAD}{ }^{+}$. These results show that the E354G mutation almost eliminated the need for $\mathrm{NAD}^{+}$for activation of the enzyme in the reverse reaction in which $\mathrm{NADH}$ serves as substrate.

Increasing the concentration of $\mathrm{NADH}$, a substrate for the reverse reaction, increased the LPD activity until the highest activity was reached at about $30 \mu \mathrm{M}$ NADH for the native enzyme (Fig. 3c). NADH beyond this concentration inhibited the reverse reaction as reported previously (Sahlman \& Williams, 1989), and at $0.3 \mathrm{mM} \mathrm{NADH}$, the native enzyme only retained about $10 \%$ of the highest observed activity. In these experiments, the concentration of $\mathrm{NAD}^{+}$as an activator was $0.1 \mathrm{mM}$. Increasing the $\mathrm{NAD}^{+}$concentration partially reversed the NADH inhibition of native LPD activity. The mutated forms of LPD required a higher concentration of $\mathrm{NADH}$ for maximal activity (about $100 \mu \mathrm{M}$ ), indicating a higher apparent $K_{\mathrm{m}}$ for NADH that is in accordance with the observed higher 

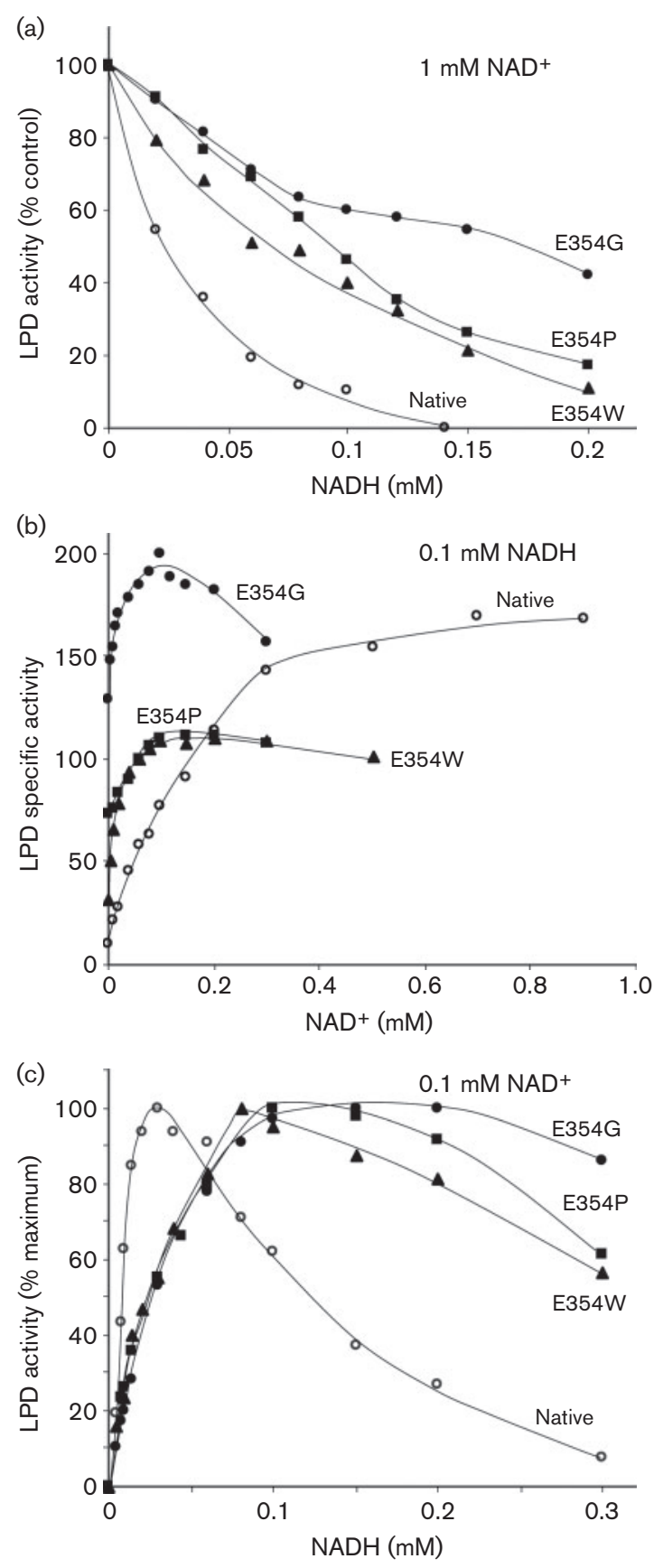

Fig. 3. Effect of changing glutamate at position of 354 on NADH sensitivity of $E$. coli LPD. (a) LPD forward reaction was assayed with $1 \mathrm{mM} \mathrm{NAD}^{+}$as substrate and increasing concentrations of $\mathrm{NADH}$ as inhibitor. Specific activities of LPDs without added NADH were 410, 86.2, 31.7 and 81.9 units for the native LPD and the proteins with E354G, E354P and E354W changes, respectively. (b) $\mathrm{NAD}^{+}$activation of LPD in the reverse reaction. Substrate $\mathrm{NADH}$ concentration was fixed at $0.1 \mathrm{mM}$. (c) LPD reverse reaction with $0.1 \mathrm{mM} \mathrm{NAD}^{+}$as activator. The highest observed value for each mutant was set as $100 \%$ and these values were $118,202.8,120.9$ and 115.8 units of activity for the E354E, E354G, E354P and E354W proteins, respectively. apparent $K_{\mathrm{i}}$ for NADH in the forward reaction (Table 4). These mutated forms of the LPD were also less sensitive to $\mathrm{NADH}$ inhibition compared with the native enzyme in the reverse reaction. These results are in agreement with the observation that the amino acid changes at position 354 result in a protein with a lower affinity for NADH than the native enzyme.

Apparently, this difference in NADH sensitivity of the LPD and the resulting PDH complex is responsible for the observed PDH-dependent anaerobic growth of the mutants.

\section{Homology modelling of $E$. coli LPD}

In order to evaluate the potential structural changes in the LPD that led to the reduction in NADH sensitivity of the enzyme, a structural model of E. coli LPD was constructed. Since the E. coli LPD is yet to be defined structurally, the $N$. meningitidis LPD X-ray structure (PDB-ID, 1OJT) (Li de la Sierra et al., 1997) was used as a template for this model construction. The $64 \%$ amino acid sequence identity between these two LPDs is expected to yield similar structural arrangements between them. Since detailed Xray structures for the $\mathrm{NAD}(\mathrm{H})$-bound form of the human LPD (PDB ID, 1ZMC and 1ZMD) (Brautigam et al., 2005)

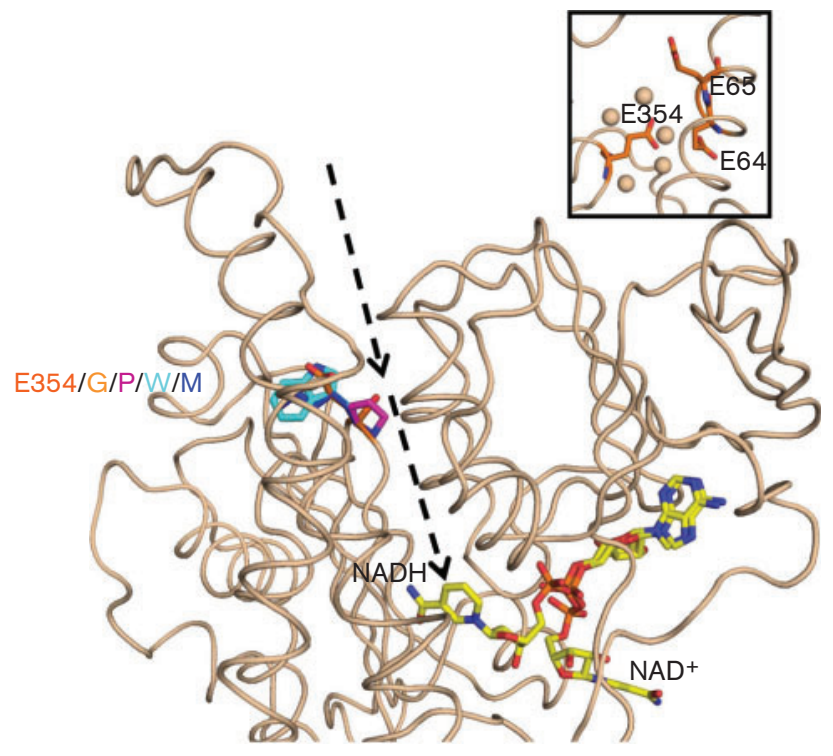

Fig. 4. Model of $E$. coli LPD monomer (coil diagram) depicting the surface-access to the NAD/NADH binding site and an interdomain conduit from the NADH binding site to surface (dotted arrows). Amino acid E354 and its various mutational alterations (G, $\mathrm{P}, \mathrm{W}$ and $\mathrm{M})$ are included in different colours. $\mathrm{NAD}^{+}$and $\mathrm{NADH}$ are depicted in stick form and coloured according to atom types. Inset: The conduit with E354 is expanded to indicate surrounding water molecules (spheres) through which E354 from one domain could interact with E64 and E65 from the other domain. Amino acids are in stick form. See text for details. 
are available, these structures were also used as templates for generation of E. coli LPD homology structure with $\mathrm{NAD}(\mathrm{H})$. The three structures were superimposed with each other and showed a root-mean-square deviation (RMSD) within $1.0 \AA$ (0.1 nm).

A structure corresponding to each of the substitutions of glutamate at position 354 (E354G, E354P, E354W and E354K) that yielded an LPD with altered NADH $K_{\mathrm{i}}$ was generated. The $\mathrm{NAD}^{+} / \mathrm{NADH}$ binding sites in E. coli LPD structure were identified by superimposition with the human LPD structure. In this structure, the binding site for the transiently bound $\mathrm{NAD}^{+}$and $\mathrm{NADH}$ is at the end of a surface-accessible cleft created by two domains of the protein (Fig. 4). Both forms of the co-factor had the same adenine dinucleotide conformation but deviated in their nicotinamide mononucleotide conformation (Fig. 4). The glutamate at position 354 appears to act as a gate-keeper in this putative channel by its potential to hydrogen bond with amino acids E64 and E65 across the channel through water molecules [about 3-4 $\AA(0.3-0.4 \mathrm{~nm})$ distance from E354] (Fig. 4, inset). Such an interaction between E354 and E64/E65 could restrict free movement of NADH to the surface with a putative decrease in the $K_{\mathrm{i}}$ of LPD to NADH (Table 4). Based on the LPD model, the methionine side chain also appears to protrude into the inter-domain channel and, as suggested for E354, methionine sulfur could hydrogen-bond across the putative conduit with E64/E65 from the other domain resulting in limited mobility of NADH from the binding pocket to the surface. Alteration of the glutamate to other amino acids, such as $\mathrm{G}, \mathrm{P}, \mathrm{W}$ or $\mathrm{K}$, probably has a negligible effect on the rate of movement of NADH through the water-filled conduit by minimizing hydrogen bonds with neighbouring amino acids across this channel. If these amino acid changes increased the ability of NADH to travel through and out of the binding site, the kinetics of association/dissociation of the substrate/inhibitor with the protein may be altered. The higher apparent $K_{\mathrm{i}}$ for NADH observed with the mutated forms of the LPD (Table 4) are in agreement with such an alteration. These results suggest that one of the causes of reduced NADH sensitivity of LPD and PDH that led to $\mathrm{PDH}$-dependent anaerobic growth and generation of homoethanol producing E. coli strains is an increase in $\mathrm{NADH}$ movement (leading to lower affinity) from the binding site in the LPD protein to the surface.

It is interesting to note that PDH has not evolved naturally towards an NADH-insensitive form that can also function anaerobically. Although all the substitutions at E-354 of LPD supported PDH activity, mutant strains with altered $\mathrm{PDH}\left(\mathrm{PDH}^{*}\right)$ grew at a significantly lower growth rate even under aerobic conditions compared with the wild-type with the native E354 form of LPD (Table S2). Even if the evolved $\mathrm{PDH}^{\star}$ in conjunction with $\mathrm{ADH}-\mathrm{E}$ can help maintain redox balance during anaerobic growth through homoethanol production, it is at the expense of an additional net ATP per glucose that can be generated by conversion of pyruvate to acetyl-CoA through PFL and further metabolism of acetyl-CoA to equimolar amounts of acetate and ethanol (Fig. 1). It is possible that the lower growth rate and reduced ATP yield per glucose during anaerobic growth diluted out spontaneously arising $\mathrm{PDH}^{\star}$ mutants in the population and yielded an evolutionary advantage to native PDH.

\section{Conclusion}

Substitution of glutamate at position 354 of LPD with any of the other natural amino acids, except methionine, led to a PDH complex that functions in an anaerobic E. coli ldhA, $p f l B$ double mutant producing ethanol as a fermentation product. In three of the substitutions, E354G, E354P and E354W, studied in detail, the alteration in LPD and the associated PDH complex lowered the affinity of the enzyme to NADH. Glutamate at position 354 is not known to interact with $\mathrm{NAD}^{+}, \mathrm{NADH}$ or FAD directly and the effect of the mutation in lowering the affinity for $\mathrm{NADH}$ is probably mediated through structural requirement of glutamate at this position as a potential gate-keeper in $\mathrm{NAD}(\mathrm{H})$ movement between the surface and the binding site in the protein.

\section{ACKNOWLEDGEMENTS}

Z.S. was supported by a scholarship from the China Scholarship Council during this study. We thank Dr Zhenjun Sun for his support. This study was supported in part by grants from the Department of Energy (DE-FG36-04GO14019 and DE-FG36-08GO88142), US Department of Agriculture, National Institute of Food and Agriculture (2011-10006-30358), the State of Florida, University of Florida Agricultural Experiment Station and the Florida Energy Systems Consortium.

\section{REFERENCES}

Arnold, K., Bordoli, L., Kopp, J. \& Schwede, T. (2006). The swissMODEL workspace: a web-based environment for protein structure homology modelling. Bioinformatics 22, 195-201.

Ausubel, F. M., Brent, R., Kingston, R. E., Moore, D. D., Smith, J. A., Seidman, J. G. \& Struhl, K. (1987). Current Protocols in Molecular Biology. Brooklyn, NY: Greene Publishing Associates and WileyInterscience.

Benen, J., van Berkel, W., Zak, Z., Visser, T., Veeger, C. \& de Kok, A. (1991). Lipoamide dehydrogenase from Azotobacter vinelandii: sitedirected mutagenesis of the His450-Glu455 diad. Spectral properties of wild type and mutated enzymes. Eur J Biochem 202, 863-872.

Bisswanger, H. (1981). Substrate specificity of the pyruvate dehydrogenase complex from Escherichia coli. J Biol Chem 256, 815-822.

Bisswanger, H. \& Henning, U. (1971). Regulatory properties of the pyruvate-dehydrogenase complex from Escherichia coli. Positive and negative cooperativity. Eur J Biochem 24, 376-384.

Bock, A. \& Sawers, G. (1996). Fermentation. In Escherichia coli and Salmonella: Cellular and Molecular Biology, pp. 262-282. Edited by F. C. Neidhardt,, R., III, J. L. Ingraham, E. C. C. Lin, K. B Low, B. Magasanik, W. S. Reznikoff, M. Riley, M. Schaechter \& H. E. Umbarger. Washington, DC: American Society for Microbiology. 
Bradford, M. M. (1976). A rapid and sensitive method for the quantitation of microgram quantities of protein utilizing the principle of protein-dye binding. Anal Biochem 72, 248-254.

Brautigam, C. A., Chuang, J. L., Tomchick, D. R., Machius, M. \& Chuang, D. T. (2005). Crystal structure of human dihydrolipoamide dehydrogenase: $\mathrm{NAD}^{+} / \mathrm{NADH}$ binding and the structural basis of disease-causing mutations. J Mol Biol 350, 543-552.

Cameron, J. M., Levandovskiy, V., Mackay, N., Raiman, J., Renaud, D. L., Clarke, J. T., Feigenbaum, A., Elpeleg, O. \& Robinson, B. H. (2006). Novel mutations in dihydrolipoamide dehydrogenase deficiency in two cousins with borderline-normal PDH complex activity. Am J Med Genet A 140, 1542-1552.

Cassey, B., Guest, J. R. \& Attwood, M. M. (1998). Environmental control of pyruvate dehydrogenase complex expression in Escherichia coli. FEMS Microbiol Lett 159, 325-329.

Clark, D. P. (1989). The fermentation pathways of Escherichia coli. FEMS Microbiol Rev 5, 223-234.

Datsenko, K. A. \& Wanner, B. L. (2000). One-step inactivation of chromosomal genes in Escherichia coli K-12 using PCR products. Proc Natl Acad Sci U S A 97, 6640-6645.

Davis, R. W., Botstein, D. \& Roth, J. R. (1980). Advanced Bacterial Genetics. Cold Spring Harbor, NY: Cold Spring Harbor Laboratory.

de Graef, M. R., Alexeeva, S., Snoep, J. L. \& Teixeira de Mattos, M. J. (1999). The steady-state internal redox state (NADH/NAD) reflects the external redox state and is correlated with catabolic adaptation in Escherichia coli. J Bacteriol 181, 2351-2357.

Emsley, P., Lohkamp, B., Scott, W. G. \& Cowtan, K. (2010). Features and development of Coot. Acta Crystallogr D Biol Crystallogr 66, 486501.

Guest, J. R. (1995). The Leeuwenhoek Lecture, 1995. Adaptation to life without oxygen. Philos Trans R Soc Lond B Biol Sci 350, 189-202.

Hansen, H. G. \& Henning, U. (1966). Regulation of pyruvate dehydrogenase activity in Escherichia coli K12. Biochim Biophys Acta 122, 355-358.

Hopkins, N. \& Williams, C. H., Jr (1995). Lipoamide dehydrogenase from Escherichia coli lacking the redox active disulfide: C44S and C49S. Redox properties of the FAD and interactions with pyridine nucleotides. Biochemistry 34, 11766-11776.

Kaiser, M. \& Sawers, G. (1994). Pyruvate formate-lyase is not essential for nitrate respiration by Escherichia coli. FEMS Microbiol Lett 117, 163-168.

Kim, Y., Ingram, L. O. \& Shanmugam, K. T. (2007). Construction of an Escherichia coli K-12 mutant for homoethanologenic fermentation of glucose or xylose without foreign genes. Appl Environ Microbiol 73, 1766-1771.

Kim, Y., Ingram, L. O. \& Shanmugam, K. T. (2008). Dihydrolipoamide dehydrogenase mutation alters the NADH sensitivity of pyruvate dehydrogenase complex of Escherichia coli K-12. J Bacteriol 190, 38513858.

Laemmli, U. K. (1970). Cleavage of structural proteins during the assembly of the head of bacteriophage T4. Nature 227, 680-685.

Laskowski, R. A., MacArthur, M. W., Moss, D. S. \& Thornton, J. M. (1993). PROCHECK: a program to check the stereochemical quality of protein structures. J Appl Cryst 26, 283-291.
Lee, J. H., Patel, P., Sankar, P. \& Shanmugam, K. T. (1985). Isolation and characterization of mutant strains of Escherichia coli altered in $\mathrm{H}_{2}$ metabolism. J Bacteriol 162, 344-352.

Li de la Sierra, I., Pernot, L., Prangé, T., Saludjian, P., Schiltz, M., Fourme, R. \& Padrón, G. (1997). Molecular structure of the lipoamide dehydrogenase domain of a surface antigen from Neisseria meningitidis. J Mol Biol 269, 129-141.

Miller, J. H. (1972). Experiments in Molecular Genetics. Cold Spring Harbor, NY: Cold Spring Harbor laboratory.

Murarka, A., Clomburg, J. M., Moran, S., Shanks, J. V. \& Gonzalez, R. (2010). Metabolic analysis of wild-type Escherichia coli and a pyruvate dehydrogenase complex (PDHC)-deficient derivative reveals the role of PDHC in the fermentative metabolism of glucose. J Biol Chem 285, 31548-31558.

Patel, M. S. \& Hong, Y. S. (1998). Lipoic Acid as an Antioxidant. The Role of Dihydrolipoamide Dehydrogenase. In Methods in Molecular Biology. Totowa, NJ: Humana Press.

Russell, G. C. \& Guest, J. R. (1990). Overexpression of restructured pyruvate dehydrogenase complexes and site-directed mutagenesis of a potential active-site histidine residue. Biochem J 269, 443-450.

Sahlman, L. \& Williams, C. H., Jr (1989). Lipoamide dehydrogenase from Escherichia coli. Steady-state kinetics of the physiological reaction. J Biol Chem 264, 8039-8045.

Sawers, R. G. \& Clark, D. P. (2004). Fermentative pyruvate and acetylCoenzyme A metabolism. EcoSal-Escherichia coli and Salmonella: Cellular and Molecular Biology http://ecosal.org.

Schmincke-Ott, E. \& Bisswanger, H. (1981). Dihydrolipoamide dehydrogenase component of the pyruvate dehydrogenase complex from Escherichia coli K12. Comparative characterization of the free and the complex-bound component. Eur J Biochem 114, 413-420.

Scouten, W. H. \& McManus, I. R. (1971). Microbial lipoamide dehydrogenase. Purification and some characteristics of the enzyme derived from selected microorganisms. Biochim Biophys Acta 227, 248-263.

Shen, L. C. \& Atkinson, D. E. (1970). Regulation of pyruvate dehydrogenase from Escherichia coli. Interactions of adenylate energy charge and other regulatory parameters. J Biol Chem 245, 5974-5978.

Snoep, J. L., Teixeira de Mattos, M. J., Postma, P. W. \& Neijssel, O. M. (1990). Involvement of pyruvate dehydrogenase in product formation in pyruvate-limited anaerobic chemostat cultures of Enterococcus faecalis NCTC 775. Arch Microbiol 154, 50-55.

Snoep, J. L., de Graef, M. R., Westphal, A. H., de Kok, A., Teixeira de Mattos, M. J. \& Neijssel, O. M. (1993). Differences in sensitivity to $\mathrm{NADH}$ of purified pyruvate dehydrogenase complexes of Enterococcus faecalis, Lactococcus lactis, Azotobacter vinelandii and Escherichia coli: implications for their activity in vivo. FEMS Microbiol Lett 114, 279283.

Underwood, S. A., Buszko, M. L., Shanmugam, K. T. \& Ingram, L. O. (2002). Flux through citrate synthase limits the growth of ethanologenic Escherichia coli KO11 during xylose fermentation. Appl Environ Microbiol 68, 1071-1081.

Edited by: G. H. Thomas 